\title{
Update on main situations of conflict-induced displacement
}

UNHCR on behalf of the IDP Task Forces - where the transition of overall coordination to OCHA has not yet taken place

11 November 2015 


\section{Key elements of displacement figures (end Sept.)}

Consolidated October data still being analyzed

- Almost 28,000 new displaced IDPs assessed/profiled in September (i.e. Before Kunduz crisis)

- In Sept $2015 \rightarrow$ North East approx. 9,200 new IDPs; Central region approx. 5,700; East approx. 3,850; North approx 3,100; South approx. 1950

- Displacement situations in September in line with last months trends, with prevalence North/ North East and East

- Since January $2015 \rightarrow 235,200$ ind./36,480 fam. newly profiled as conflict-IDPs; of those 196,700 ind./30,450 fam. displaced in 2015 (approx. 84\%)

- Newly displaced in 2015 (January - end September) $\rightarrow$ 65\% increase from same period in 2014

- Newly displaced in 2015 (end September) already surpassed the whole fresh displacement of 2014 (190,000 by end 2014) 


\section{Key displacement figures (end Sept.)}

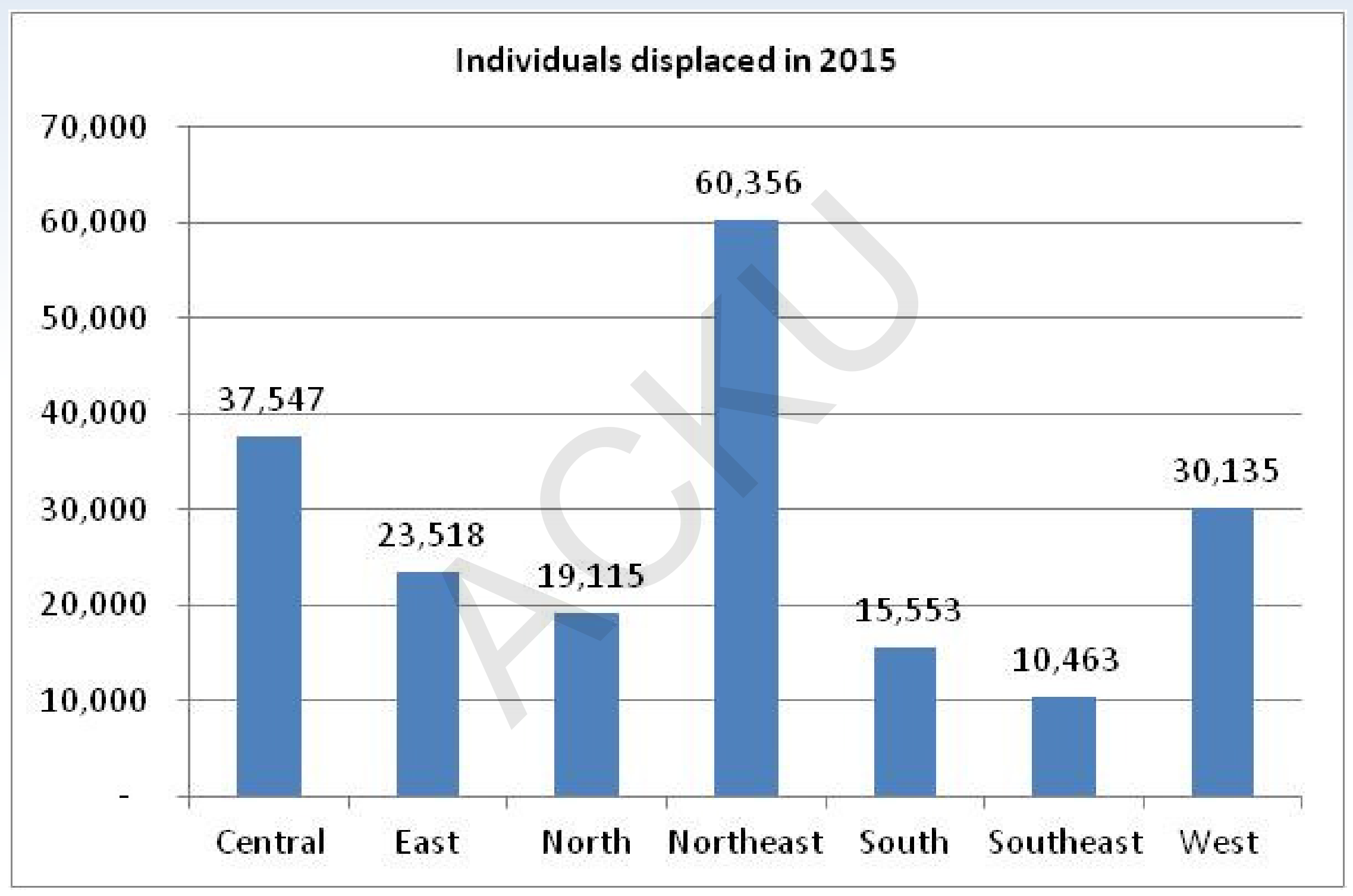




\section{Key displacement figures (end Sept.)}

Provinces with more than 5,000 individuals displaced in 2015

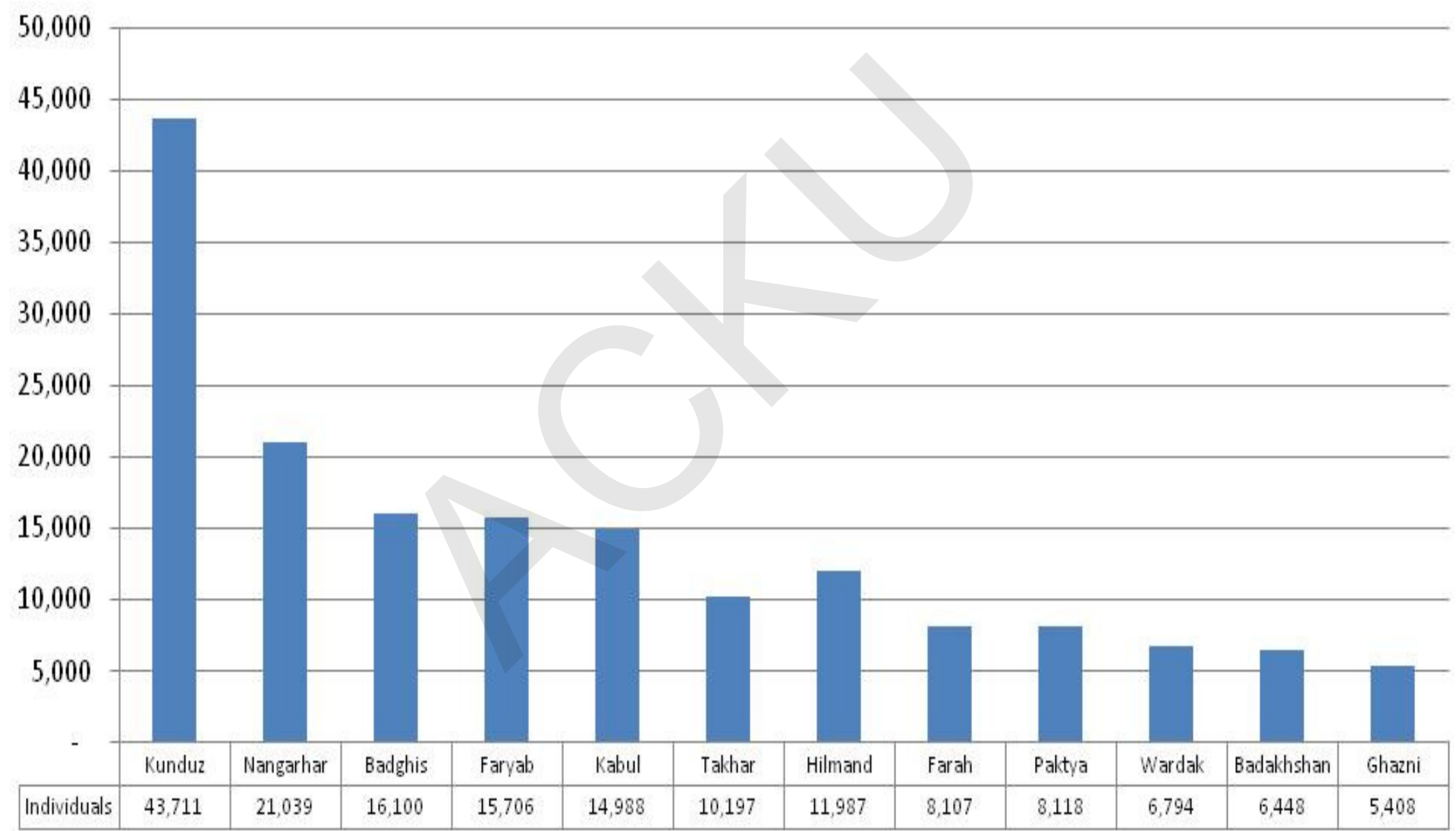




\section{East - Nangarhar Province}

- Jan. - end Sept. $\rightarrow$ more than 4,700 fam./ 28,100 ind. profiled in 2015 of whom some 3,850 fam./ 23,500 ind. Displaced in 2015

- Since mid-June to end October continuous influx of IDPs from Kot and Achin districts fleeing clashes between non-State actors

- Increasing fragmentation of NSAG and reported episodes of unprecedented level of violence prompting families to flee

- Since August $\rightarrow$ growing numbers of IDPs from Kot and Achin reported in Central Region/ Kabul Province (including urban area) $\rightarrow$ Continuous contacts between IDP TFs Kabul and Nangarhar

- New waves of displacement from September following intensification of conflict in Achin (IS/DAESH affiliated VS Taleban; clashes with ANSF)

- New intensification of arrivals during the first weeks of November

- Severe increase in the series of notifications/ petitions from different districts of Nangarhar, including Kot and Achin $\rightarrow$ assessment mobilised but serious concern of lack of resources for the assessment (Earthquake) 


\section{East - Nangarhar Province}

- KOT/ACHIN: Almost 10,131 fam. petitioning/5,230 families assessed / 6,315 families/ approx. 31,000 ind. defined as genuine IDPs (77\%)

Kot displacement (as of 10 November): Assessment is still ongoing

- 301 notifications (3,211 fam.) shared by DoRR

- IDP TF jointly assessed 1,955 families

- 1,173 fam./6,520 ind. (61\%) profiled as genuine IDP

- Response so far all committed/ covered for 809 families; some 364 families still to be assisted /covered; assessment ongoing

- Families displaced to multiple villages of Bihsud (49.5\%), Surkhrud (21\%), Jalalabad city (4.6\%), and Rodat (18.8\%) districts

- Joint contribution by multiple humanitarian actors ERM partners (NRC and DCR with cash in lieu of food and NFI), WFP (food), UNHCR (NFI) and IRC (NFI)

- Government soliciting return to Kot areas where control has been reestablished. Importance to uphold the principle of voluntary/ safe/ dignified/ sustainable return 


\section{East - Nangarhar Province}

\section{Achin displacement (as of 10 November):}

- 216 notification letters (6,845 fam.) received from DORR Nangarhar

- TF jointly and ICRC/ARCS assessed 4,337 fam. displaced from Achin

- Some 3,662 fam./24,000 ind (85\%) considered genuine IDPs in need

- Response so far all committed/ covered for 3,629 fam.

- Joint contribution UN agencies and ERM partners but majority of the IDPs (57\% fam.) assessed and assisted by ARCS/ICRC

- Assessment ongoing for new petitions

- Displacement to different villages particularly in Ghani Khel (33.6\% due to tribal affiliation); other areas in Achin District (12.6\%);

Mohamandara (18\%), Surkhrud (7\%), Dur Baba (5.2\%); other locations in the province (Bihsud, Chaparhar, Jalalabad City, Rodat).

- Many families reported in dire conditions

- Multiple displacement in the East $\rightarrow$ So far assistance covered BUT assessment teams severely overstretched (including earthquake efforts) while trying to maintain integrity of the assessment process 


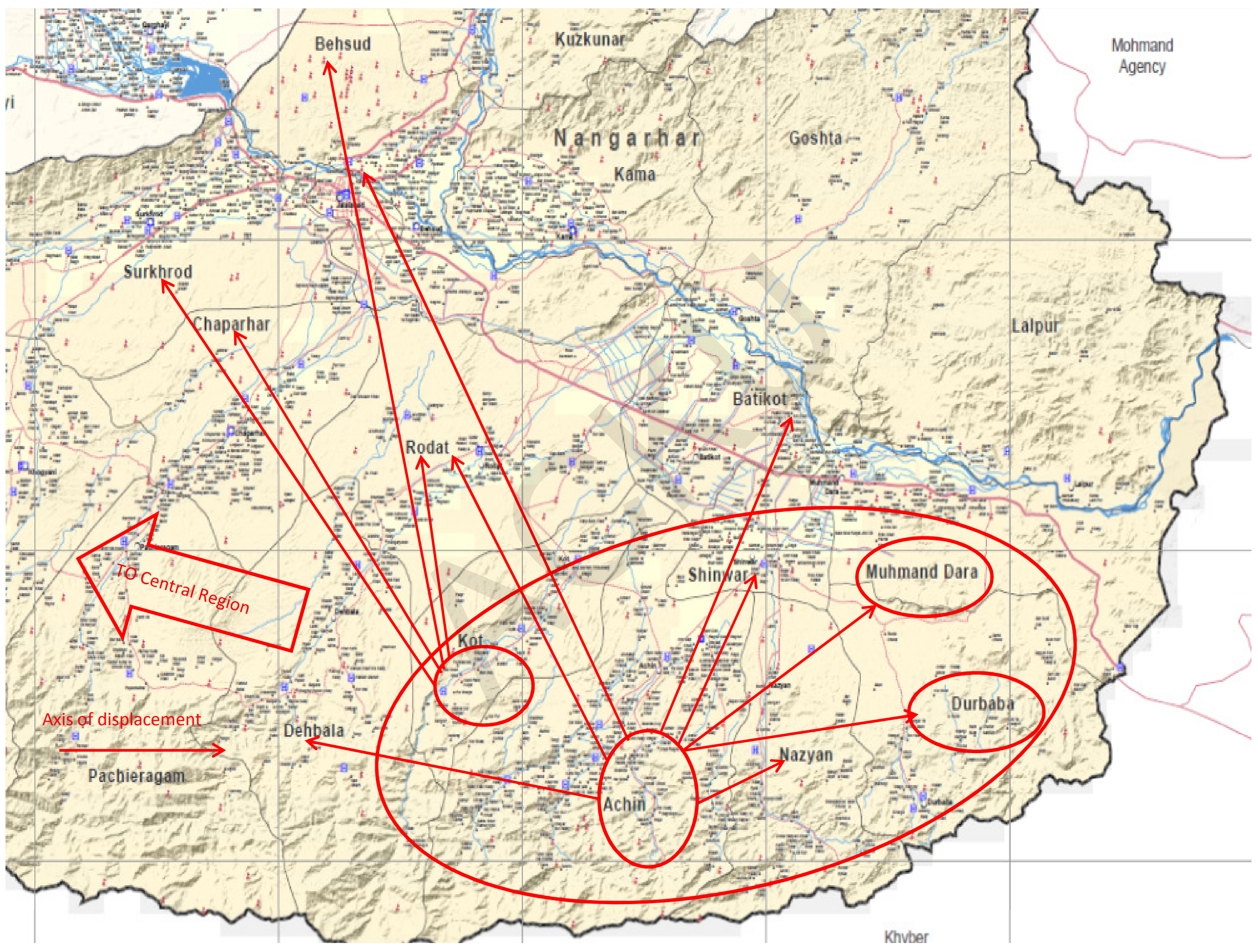




\section{Kabul/ Central Region}

- Increased pressure on the Central Region/ Kabul due to multiple factors

- Displacement from within the region AND displacement from outside the region

- Since Mid-June continuous influx of IDPs from Kot and Achin districts fleeing clashes between non-State actors

- Kunduz displacement, before the crisis and following the recent crisis

- Multiple waves of displacement overlapping and increasing demands on assessment teams

- Complex assessment environment (urban caseload) and vast rural area to cover

- Jan - Sept $\rightarrow$ some 8,200 fam. / 54,500 ind. profiled of whom 5,720 fam./ 37,500 ind. displaced in 2015

- Presence of large backlog of petitions who were de-prioritised due to the pressure over the response to Kunduz and now being processed $\rightarrow$ Still some 4,800 petitions to be assessed (Eastern / Central region) 


\section{Kabul/ Central Region}

- Kunduz Displacement highlights / process concluded

- Since beginning of October 10 to 14 teams mobilised (Government, UN, Humanitarian actors: WSTA/ UNHCR, WFP, OCHA, DRC, IRC, Care, Focus, IOM, ANDMA, MoRR, DORR, ARCS).

- Attempt to engage DowA and MoSa highlighted by protection actors

- 5,551 petitioning families (list from MORR as official provider)

- 4,661 families assessed, 740 not found in the area

- 3,484 found as genuine IDPs (75\%), but increasing trends of petitions including local residents and KIS residents

- 3,019 were found in need for assistance

- Some last 600 petitions related to the Kunduz crisis may need to be screened by MORR before being assessed; still no development

- Challenging process of assessment $\rightarrow$ mobility of families delays the assessment; rapid cycle of displacement and return process; availability of staff for assessment teams; commitment and resources from the governmental teams; political pressure to speed assessment; inflated lists (local residents/ KIS) 


\section{Kabul/ Central Region}

- Kunduz Displacement highlights (11 November)

- Assistance delivery to families still displaced in process

- 2,127 families assisted up to 11 November (food WFP, NFI UNHCR); distribution continues

- Challenges in distribution: Assistance provided to IDP families only attending the distribution in person (not relatives, neighbours etc.); distribution had to be suspended and resumed

- More than 1,000 families listed with MORR for return assistance and assisted by Government

- Understanding return trends $\rightarrow$ IDP Task Force partner tasked to call all assessed families to ascertain the return. So far some 1,500 families called ( $45 \%$ of the assessed) and 270 families (18\%) reported their return. Exercise to continue. 


\section{Kabul/ Central Region}

- Other displacement (from East and Central Region)

- Some 4,800 families filing petitions since September

- 700 of those families in areas non accessible to the IDP TF (Kapisa) $\rightarrow$ dialogue with ICRC/ARCS;

- Some other 300 may have returned already to Kapisa

- IDP Task Force 2 November $\rightarrow$ Mobilization of teams for assessment of other petitions received during/ before Kunduz crisis (some 3,800)

- Assessment started in Logar, Maidan Wardak, Ghazni and Kabul on $4^{\text {th }}$ November (see after)

- 5 Teams of 3 persons mobilised (DORR, UNHCR/WSTA, WFP, OCHA, DRC, Care, Dacaar); one female staff in all teams

- 1,060 families assessed (4-11 November); 594 families as genuine IDPs (56 \%); 326 in need of assistance (174 Kabul, 62 Maidan, 34 Ghazni, 56 Logar) $\rightarrow$ distribution to start as soon as all assistance for Kunduz IDPs delivered

- Assessment continues in PD 5,6,7,10,12,16 


\section{Southern Region}

- Jan - Sept $\rightarrow$ some 2,350 fam./ 18,500 ind. profiled of whom 1,950 fam./ 15,600 ind. displaced in 2015

\section{COMPLETED ASSESSMENTS AND ASSISTANCE DELIVERED}

\begin{tabular}{|c|c|c|c|c|}
\hline \multicolumn{5}{|c|}{$\begin{array}{c}\text { Assessments conducted in SR as of } 14 \text { September } 2015 \\
\text { and assistance delivery }\end{array}$} \\
\hline & $\begin{array}{l}\text { Date of } \\
\text { Assessments }\end{array}$ & Province & Families verified & Individuals \\
\hline 1 & January & Kandahar & 150 & 1,066 \\
\hline 2 & March & Kandahar & 93 & 697 \\
\hline 3 & June & Kandahar & 210 & 1,653 \\
\hline 4 & January & Helmand & 93 & 692 \\
\hline 5 & January & Helmand & 78 & 638 \\
\hline 6 & March & Helmand & 304 & 2,406 \\
\hline 7 & March & Helmand & 70 & 532 \\
\hline 8 & April & Helmand & 169 & 1,290 \\
\hline 9 & April & Helmand & 105 & 942 \\
\hline 10 & May & Helmand & 82 & 621 \\
\hline 11 & May & Helmand & 48 & 375 \\
\hline 12 & June & Helmand & 86 & 731 \\
\hline 13 & June & Helmand & 8 & 75 \\
\hline 14 & September & Helmand & 362 & 2,882 \\
\hline 15 & September & Helmand & 178 & 1,436 \\
\hline 16 & September & Helmand & 24 & 200 \\
\hline 17 & January & Urozgan & 69 & 591 \\
\hline 18 & March & Urozgan & 22 & 199 \\
\hline 19 & June & Urozgan & 44 & 375 \\
\hline 20 & August & Urozgan & 76 & 642 \\
\hline 21 & September & Nimroz & 125 & 856 \\
\hline \multicolumn{3}{|c|}{ Total: } & 2,396 & 18,899 \\
\hline
\end{tabular}




\section{Southern Region}

- Up to $1^{\text {st }}$ October all accessible displacement assessed and assisted (largely Helmand, minor in Kandahar, Uruzgan, Nimrooz)

- Continuous challenges in access (northern Helmand, Northern Uruzgan) hamper assessment of real magnitude of the displacement (cooperation ARCS/ ICRC)

- Recent growing instability in Northern Helmand, North Uruzgan, Farah generating new displacement to Southern region

- Possible increase in the overall projections for end year

- Recent deterioration of situation in Lashkar Gah insurgency presence in the outskirts of town (Baba Jee areas and Nada Ali); fresh displacement triggered

- IDP Task Force joint teams mobilised since $1^{\text {st }}$ October to assess ad assist displaced families (including DoRR, ANDMA, UNHCR/APA, OCHA, WFP, DRC, NRC, SCl, IRC, other line dep.) 


\section{Southern Region}

- IDP Task Force 18 October $\rightarrow$ agrees on multiple assessments

- Uruzgan: insecurity in the North triggering displacement to TrinKot District Centre (accessible) with 120 families indicated and possible displacement in Derawood /Chora

- Nimrooz: spill-over effect from Farah province, indication of some 100 families and assessment ongoing

- Zabul: possible displacement from northern areas due to reported confrontation Taliban/ IS-DAESH affiliated groups

- Displacement still not quantified and largely in non-accessible areas (Kakar, Day Chopan, Arghandar) and to Shajyoi District (partially accessible) and Qalat (accessible)

- Emergency PDMC meeting in Zabul (9 November) receives unconfirmed reports from DORR of displaced families

- Initial verification in Qalat (Hazari and Sinak and other villages visited) but no evidence of displacement found

- Initial verification in Shajyoi (some 100 fam. Reported by DORR) will be undertaken in the upcoming days

- Dialogue with ARCS/ICRC for verification to non-accessible areas 


\section{Southern Region}

- Serious deterioration of the situation in LK, Marja, Nada Ali

- Reported intensification of clashes; rising number of civilian casualties and families with wounded civilians in LK

- Conflict reported again at the outskirt of LK (PD4)

- Marja $\rightarrow$ Recent reports of AGEs positions close to District Administration

- Areas in Nada Ali and Marja earlier accessible to the IDP TF are now cut-off due to active conflict

- Continuous arrival of IDP families in LK since beginning October (first week) now rapidly increasing

- Difficult communication and liaison with teams due to communication disruption 


\section{Southern Region}

- Health facilities functioning in LK hosting increasing number of war wounded; patients transferred (including during assessment); health facilities in Marjia affected by conflict

- 2 Joint assessment teams (HCR/APA, UNICEF, WFP, WHO, ACF, NRC, DRC, PDMC, DoRR, Governor Office)

- $\mathbf{7 7 5}$ families so far identified; $\mathbf{3 0 0}$ assisted (UNHCR, WFP);

- other 300 to be assisted in the next days (UNHCR, WFP);

- further commitment from INGOs (ERM partners)

- Profile of IDPs $\rightarrow$ largely complete families

- Mainly accommodated in hosting arrangements BUT some few families in open air assisted with tents (UNHCR)

- Continuing assessment as access is allowed and security situation allows 







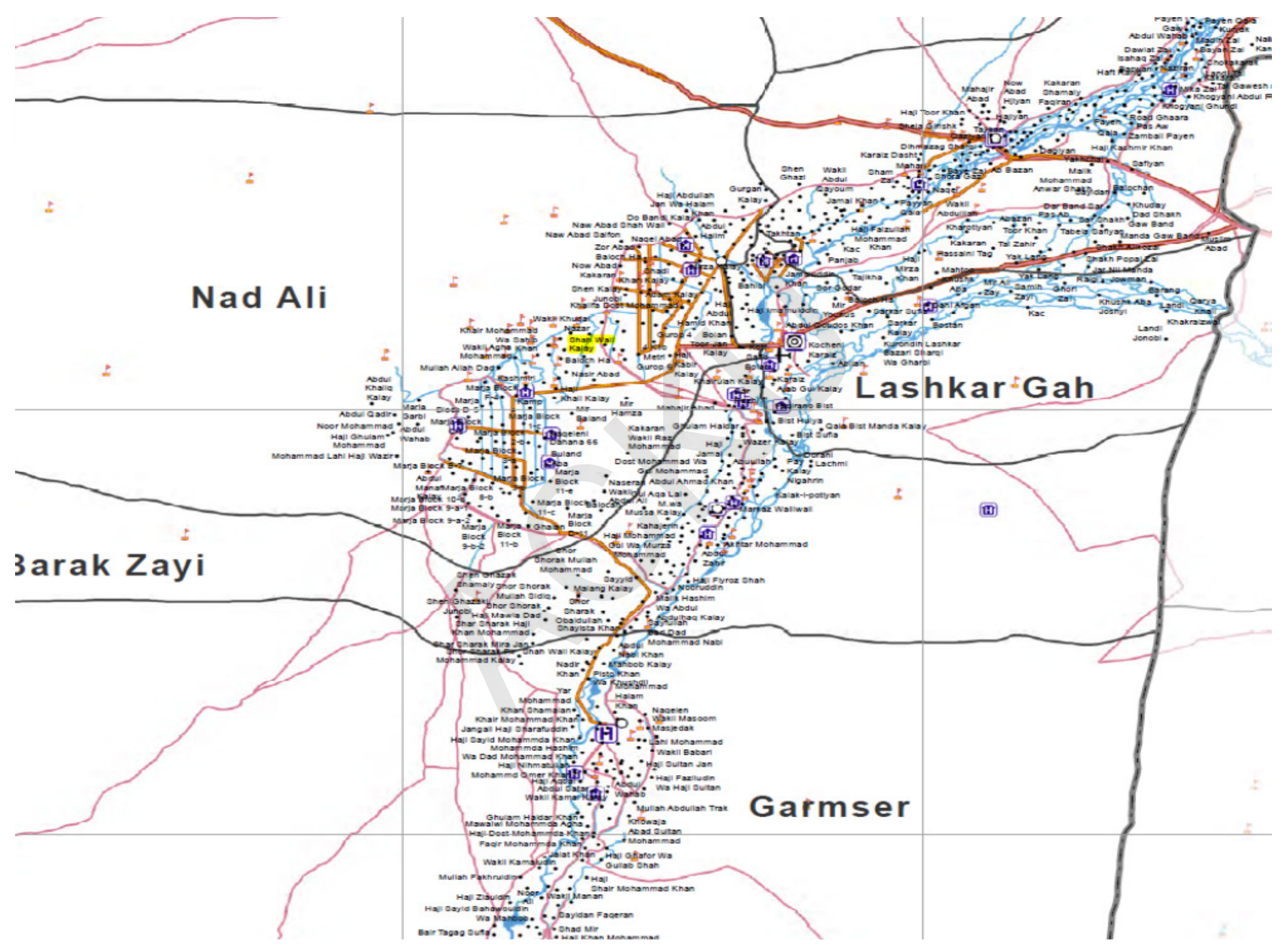

